\title{
ANÁLISE DE UM CASO CLÍNICO DE TDAH E SUAS CONSEQUENCIAS NO CONTEXTO FAMILIAR, SOCIAL E EMOCIONAL
}

\author{
Márcia Soares da Silva ${ }^{1}$
}

\begin{abstract}
RESUMO: O Transtorno do Déficit de Atenção com Hiperatividade (TDAH) é um problema bastante comum e se caracteriza pela movimentação excessiva do indivíduo, falta de atenção, impaciência, impulsividade, distração, e isso lhe traz problemas de rejeição, baixa auto-estima e várias situações que, com a devida medida podem ser minimizadas ou mesmo eliminadas. Por isso, o TDAH é considerado o transtorno mais diagnosticado na atualidade e se apresenta como tema frequente e controverso na sociedade. Pois, os valores e significados que subjazem as concepções sobre este assunto se refletem no modo como as pessoas manejam a situação. Partindo dessas premissas, este estudo analisou um caso clínico de TDAH e suas consequências no contexto familiar, social e emocional salientando a complexidade do fenômeno ao abordar a diversidade de influências que o envolve. A metodologia foi através de entrevista narrativa para analisar a história de um jovem diagnosticado com tal transtorno. A partir daí, os resultados apontaram que, a percepção da família do jovem sobre o transtorno é individualizante, patologizante, e o conhecimento, inconsistente. Assim sendo, sugere-se que este tema seja debatido em maior profundidade, pois, devido à falta de informação, muitos pais passam por dificuldade de relacionamento com crianças com TDAH, bem como é possível imaginar o quanto as gerações anteriores devem ter sofrido, passando por situações difíceis sem ao menos ter consciência do distúrbio. Entretanto, um tratamento adequado supõe intervenção psicológica, pedagógica e médica, e técnicas de mudança de comportamento, que envolva todas essas áreas, incluindo o treinamento dos pais.
\end{abstract}

Palavras-chave: TDAH, emocional, família, sociedade.

\section{ANALYSIS OF A CLINICAL ADHD CASE AND ITS CONSEQUENCES IN THE FAMILY, SOCIAL AND EMOTIONAL CONTEXT}

\begin{abstract}
The Attention Deficit Disorder with Hyperactivity (ADHD) is a fairly common problem and is characterized by excessive movement of the individual, inattention, impatience, impulsivity, distractibility, and this brings problems of rejection, low self-esteem and various situations that, with proper measurement can be minimized or even eliminated. Thus, ADHD is considered the most commonly diagnosed disorder in the present and introduced himself as frequent and controversial issue in society. For the values and meanings underlying conceptions on this subject are

\footnotetext{
${ }^{1}$ Formada em Pedagogia, especialista em Educação Especial, Psicopedagogia, Pedagogia Empresarial e MBA em Gestão de Pessoas. Mestranda do curso de Ciências Sociais pela Universidade Estadual de Maringá - UEM. E-mail: marciamga019@gmail.com.
}

Programas de Pós-Graduação em Ciências Sociais e Filosofia - UNIOESTE - Rua da Faculdade 645. Toledo - PR. CEP 85.903-000 Email: revistaalamedas@gmail.com 
reflected in how people deal with the situation. Based on these assumptions, this study analyzed a clinical case of ADHD and its consequences in the family context, emphasizing the social and emotional complexity of the phenomenon to address the diversity of influences that surrounds it. The methodology was through narrative interview to review the story of a young man diagnosed with the disorder. From there, the results indicated that the perception of the young family about the disorder is individualizing, pathologizing, and knowledge, inconsistent. Therefore, it is suggested that this issue be discussed in greater depth, by reason of the lack of information, many parents go through difficulties in relationships with children with ADHD, as well as you can imagine how previous generations must have suffered, from through difficult situations without even being aware of the disorder. However, proper treatment involves psychological intervention, educational and medical, and behavior change techniques, involving all of these areas, including parent training.

Keywords: ADHD, emotional, family, society.

\section{INTRODUÇÃO}

O Transtorno do Déficit de Atenção com Hiperatividade (TDAH) é um transtorno neurobiológico, de causas genéticas, que aparece na infância e frequentemente acompanha o indivíduo por toda a sua vida, caracterizando-se por sintomas de desatenção, inquietude e impulsividade. É reconhecido oficialmente por vários países e pela Organização Mundial da Saúde (OMS), e em alguns países, como nos Estados Unidos, os portadores são protegidos pela lei quanto a receberem tratamento diferenciado na escola.

O TDAH é o transtorno mais comum em crianças e adolescentes encaminhados para serviços especializados, e ocorre em 3 a 5\% das crianças, em várias regiões diferentes do mundo em que já foi pesquisado. E, em mais da metade dos casos o transtorno acompanha o indivíduo na vida adulta. Porém, muitos adultos com o transtorno nunca são diagnosticados porque seus sintomas predominantes são déficit de atenção, impulsividade e desorganização, ao invés da tradicional hiperatividade apresentada pelas crianças acometidas por esse transtorno. E, ao longo do crescimento, a hiperatividade diminui, enquanto que a desatenção permanece inalterada ou torna-se mais evidente à medida que aumentam a complexidade do trabalho escolar e as demandas profissionais.

Devido a esses argumentos, é que surgiu a idéia do presente tema "Análise de um caso clínico de TDAH e suas consequências no contexto familiar, social e 
emocional" com o objetivo de analisar a história de um jovem diagnosticado com tal transtorno. Pois, apesar do transtorno de déficit de atenção e hiperatividade (TDAH) atingir até $6 \%$ da população, o mesmo é ainda bastante desconhecido, inclusive por muitos profissionais da saúde, que acabam por tratar apenas das suas consequências.

O indivíduo que tem TDAH pode ser inteligente, criativo e talentoso, mas não consegue realizar todo seu potencial em função do transtorno. Nesse sentido, vale ressaltar que, a falta de diagnóstico e tratamento correto, conduz a grandes prejuízos à vida profissional, social, pessoal e emocional da pessoa portadora. E, sem tratamento, outros distúrbios podem associar-se ao quadro, a auto-estima fica cada vez mais comprometida e a pessoa vai se isolando do mundo.

\section{TDAH: HISTÓRICO E CONCEITO}

Segundo Rohde; Benczik (1999), em 1902, a ciência médica começou a notar pela primeira vez, crianças que apresentavam falta de atenção, impulsividade e hiperatividade à semelhança de adultos que haviam sofrido lesão cerebral no lobo frontal direito. Desde então, a deficiência teve vários nomes, como Disfunção Cerebral Mínima e Reação Hipercinética da Infância.

Em 1980, o diagnóstico de Transtorno de Déficit de Atenção foi realmente reconhecido no Diagnostic and Statistical Manual, 3rd Edition (DSM III) - o Manual de Diagnóstico da Associação Americana de Psiquiatria - também adotado no Brasil como referencial para diagnóstico dos problemas de saúde mental. A versão revisada de 1984 agregou o termo Hiperatividade, de modo que se tem hoje, oficialmente, o Transtorno de Déficit de Atenção/Hiperatividade (ROHDE, Benczik, 1999).

De acordo com Gotah (2001), crianças com TDAH não são incapazes de aprender, mas têm dificuldade na escola por causa da falta de organização, de atenção e da impulsividade. Algumas crianças com esse transtorno também apresentam realmente, um problema de aprendizagem, complicando ainda mais o diagnóstico e posterior tratamento. Um número significativo de crianças com TDAH - talvez em torno de $50 \%$ - jamais foi corretamente diagnosticado. 
Crianças portadoras de TDAH não costumam apresentar, em sua rotina diária, sinais sérios de problemas emocionais. Entretanto, se não forem adequadamente diagnosticadas e tratadas, podem desenvolver dificuldades emocionais importantes, como problemas de comportamento, depressão e, até mesmo, abuso de substâncias químicas (GOTAH, 2001, p.5-6).

Mattos (2001) ainda complementa que, é comum dizer que, crianças, adolescentes e adultos que têm dificuldades de atenção, "vivem no mundo da lua", isto é, parecem estar sempre pensando em outra coisa quando se fala com eles, quando estão estudando ou lendo, quando estão trabalhando, enfim, em uma grande variedade de situações. Na maioria dos casos, estas pessoas também são inquietas, que vivem trocando de interesses e planos e têm dificuldades em levar as coisas até o fim. Elas podem ter dificuldades na sua vida acadêmica, bem como na sua vida profissional, social, emocional e familiar. E, apesar de este problema ser muito frequente e causar vários problemas na vida do indivíduo, pode ficar muito tempo - ou até mesmo a vida inteira - sem ser diagnosticado e tratado de modo correto.

Porém, Mattos (2001) deixa claro que, o TDAH é um dos transtornos mais bem estudados na medicina e os dados gerais sobre sua validade são muito convincentes.

\section{CAUSAS}

Em 1990 o New England Journal of Medicine publicou o resultado de estudo feito por pesquisadores do Instituto Nacional de Saúde Mental que se tornou um marco. Dessa forma, técnicas avançadas de neuroimagem foram utilizadas para comparar o metabolismo do cérebro de adultos com e sem TDAH. $\mathrm{O}$ estudo documentou que adultos com TDAH utilizam glicose - a maior fonte de energia do cérebro - numa proporção menor que adultos sem TDAH. Esse metabolismo reduzido estava mais evidente na área do cérebro responsável pela atenção, escrita, controle motor e inibição de respostas. Esses estudos do metabolismo do cérebro, combinados com dados de outros estudos sobre histórico familiar e consequências de abuso de drogas, convenceram os pesquisadores que o TDAH é um transtorno neurobiológico, não provocado por um ambiente familiar caótico (GOTAH, 2001, p.6-7). 


\begin{abstract}
Não existe uma causa única perfeitamente estabelecida. Mas existem várias evidências que foram sendo acumuladas com as descobertas científicas das últimas décadas. Em $1^{\circ}$ lugar sabemos que existe uma participação genética no transtorno. Quando se diz que uma determinada enfermidade ou transtorno sofre influência genética, não significa que todos os indivíduos daquela família, do lado materno ou paterno também sofram do mesmo mal. Significa apenas que a incidência do problema é bem maior naquela família do que seria esperado matematicamente pelo acaso (MATTOS, 2001, p.43).
\end{abstract}

Gotah (2001) também complementa que, fatores externos também chamados de ambientais já foram considerados muito importantes antigamente, o que valeu ao TDAH os nomes de lesão cerebral mínima e disfunção cerebral mínima. Esses nomes indicavam que embora houvesse um comportamento "orgânico" ou neurológico este era de pequena monta. Estes comprometimentos eram secundários a vários fatores que poderiam afetar o sistema nervoso do feto ou da criança, ainda em desenvolvimento.

E, Mattos (2001) ressalta que, já existiram teorias das mais variadas no que diz respeito a esses fatores, tais como: aditivos alimentares; excesso de açúcar na alimentação; luz fluorescente; deficiências de vitaminas; problemas na tireóide, entre outros. E, nenhuma delas revelou-se sólida o suficiente e todas foram abandonadas. Porém, alguns fatores ainda são considerados importantes, tais como problemas no parto, uso de cigarro e álcool durante a gravidez.

Segundo o Banco de Saúde (2010), o transtorno de déficit de atenção e hiperatividade é uma disfunção crônica, herdada na grande maioria das vezes, daí sua presença desde a infância. Em menor grau há fatores do meio ambiente que podem estar relacionados ao TDAH, sendo:

- A nicotina de cigarros fumados pela mãe gestante bem como bebidas alcoólicas consumidas, podem ser causas significativas de anormalidades no desenvolvimento cerebral.

- Crianças expostas ao chumbo entre 12 e 36 meses de idade pode ser outro fator; e,

- Problemas neonatais como falta de oxigênio, traumas obstétricos, rubéola intra-uterino, encefalite, meningite pós-natal, subnutrição e traumatismo craniano são fatores que também podem contribuir para o surgimento do TDAH.

\title{
SINTOMAS DO TDAH EM CRIANÇAS E ADOLESCENTES
}

Programas de Pós-Graduação em Ciências Sociais e Filosofia - UNIOESTE - Rua da

Faculdade 645. Toledo - PR. CEP 85.903-000 Email: revistaalamedas@gmail.com 
De acordo com o Banco de Saúde (2010), o principal sintoma do TDAH é a dificuldade em manter o foco da atenção e/ou manter-se quieto, estes sintomas podem se manifestar de diversas maneiras:

- As crianças com TDAH, em especial os meninos, são agitadas ou inquietas, frequentemente têm apelido de "bicho carpinteiro" ou coisa parecida.

- $\quad \mathrm{Na}$ idade pré-escolar, estas crianças mostram-se agitadas, movendo-se sem parar pelo ambiente, mexendo em vários objetos.

- $\quad$ Mexem pés e mãos, não param quietas na cadeira.

- Falam muito e constantemente pedem para sair de sala ou da mesa de jantar.

- Têm dificuldades para manter atenção em atividades muito longas, repetitivas ou que não lhes sejam interessantes.

- São facilmente distraídas por estímulos do ambiente externo, mas também se distraem com pensamentos "internos", dando a impressão de estarem "voando".

- Nas provas, são visíveis os erros por distração (erram sinais, vírgulas, acentos, etc.).

- Pela falta de atenção, esquece recados ou material escolar, aquilo que estudaram na véspera da prova.

- $\quad$ Tendem a ser impulsivas (não esperam a vez, não lêem a pergunta até o final e já respondem, interrompem os outros, agem antes de pensar).

- $\quad$ É comum apresentarem dificuldades em se organizar e planejar aquilo que querem ou precisam fazer.

- Seu desempenho sempre parece inferior ao esperado para a sua capacidade intelectual.

Entretanto, quando os portadores de TDAH se dedicam a fazer algo estimulante ou do seu interesse, conseguem permanecer mais tranquilos. E, isto ocorre porque os centros de prazer no cérebro são ativados e conseguem dar um "reforço" no centro da atenção que é ligado a ele, passando a funcionar em níveis normais. Mas, o fato de uma criança conseguir ficar concentrada em alguma atividade não exclui o diagnóstico de TDAH, e este por sua vez, não se associa necessariamente a dificuldades 
na vida escolar, é mais comum que os problemas na escola sejam de comportamento do que de rendimento.

\section{SINTOMAS DE TDAH EM ADULTOS}

Ainda segundo o Banco de Saúde (2010), muitos médicos desconhecem a existência do TDAH em adultos e quando são procurados por estes pacientes, tendem a tratá-los como se tivessem outros problemas. E, acredita-se que em torno de $60 \%$ das crianças com TDAH mantêm o quadro na vida adulta, porém, com sintomas em menor número. Entretanto, o TDAH não surge na vida adulta, é obrigatório demonstrar que o transtorno esteve presente desde criança. Sendo que, as manifestações comuns de adultos com TDAH são:

- Ter dificuldade de organizar e planejar suas atividades do dia a dia, como por exemplo, pode ser difícil determinar o que é mais importante dentre muitas coisas que tem para fazer, escolher o que vai fazer primeiro e o que pode deixar para depois.

- Ficar "estressados" quando se vêem sobrecarregados, pois assumem vários compromissos diferentes, por não saber por onde começar.

- Deixar trabalhos pela metade, interrompem no meio o que estão fazendo e começam outra coisa, só voltando ao trabalho anterior bem mais tarde do que o pretendido ou então se esquecendo dele.

- Ter dificuldade para realizar sozinho suas tarefas, principalmente quando são muitas, e o tempo todo precisa ser lembrado pelos outros sobre o que tem para fazer.

- Persistir nas tarefas também pode ser difícil para o portador de TDAH, que frequentemente "deixa as coisas pela metade".

- $\quad$ Ter dificuldade em assistir uma palestra, ler um livro, sem que sua cabeça "voe" para bem longe perdida num turbilhão de pensamentos.

\section{DIAGNÓSTICO E TRATAMENTO}

De acordo com o Banco de Saúde (2010), o diagnóstico do transtorno de déficit de atenção com hiperatividade é realizado pelo médico, em especial o psiquiatra, por meio de história clínica, testes e avaliações, como o questionários ASRS-18 e SNAP- 
IV, exames complementares, tais como exames de sangue, avaliação da visão e audição, exames neurológicos e de imagens para descartar diagnósticos diferenciais.

O tratamento de crianças com TDAH supõe intervenção psicológica, pedagógica e médica, além de técnicas de mudança de comportamento. Uma abordagem que envolva todas essas áreas inclui: treinamento dos pais em controle do comportamento; um programa pedagógico adequado; aconselhamento individual e para a família quando necessário; medicamento, quando necessário (GOTAH, 2001, p.7).

O tratamento acima citado exige um esforço coordenado entre os profissionais das áreas médica, saúde mental e pedagógica, em conjunto com os pais. Esta é a chamada "Intervenção Multidisciplinar", mas a maioria dos médicos indica o tratamento com medicamentos.

O Banco de Saúde também complementa que, o tratamento do TDAH deve ser combinado e integrado, por meio de medicamentos, orientação aos pais e professores, e técnicas específicas que são ensinadas ao portador. A medicação é parte muito importante do tratamento, pois, em $80 \%$ dos casos ajuda a pessoa a concentrar-se, a terminar suas tarefas sem interrupções, reduz a impulsividade e a agitação. E, os medicamentos mais comumente utilizados no Brasil são: Metilfenidato, Imipramina, Nortriptilina, Bupropiona, Clonidina.

De acordo com Mattos (2001), o National Institute of Health dos E.U.A, diz que, os estimulantes são a primeira escolha no tratamento de TDAH, menos que $90 \%$ de todas as crianças em tratamento para TDAH nos E.U.A fazem uso de estimulantes. Existem quase 200 estudos clínicos, que avaliaram mais de 6.000 crianças, demonstrando que $70 \%$ respondem com um único estimulante. Portanto, não existe nenhuma outra abordagem (psicoterapia, modificação do ambiente, orientação a pais e professores) que tenha a mesma eficácia dos medicamentos. Pois, quando o portador do TDAH está usando a medicação e sua produção de neurotransmissores regulariza qualquer outra abordagem que se use, os resultados são muito melhores do que se ele não usasse medicamentos.

Ainda segundo Mattos (2001), os medicamentos ajudam a normalizar os neurotransmissores enquanto estão sendo tomados; e se interrompidos volta tudo 
novamente. É certo que com o passar do tempo os portadores do TDAH desenvolvem a capacidade de prestar mais atenção, administrar as deficiências pessoais, controlar o comportamento, porém, é importante lembrar que os remédios não curam o TDAH.

\section{CARACTERIZANDO O ESTUDO DE CASO}

O estudo de caso foi realizado através de entrevista narrativa com os pais de um jovem portador de TDAH, 19 anos, o qual será especificado como "A" no decorrer do estudo. Sendo que, atualmente "A", trabalha como entregador de água natural do Paraná, e no momento, reside em Curitiba-PR.

As dificuldades de "A" começaram desde o seu nascimento, sendo que, a gravidez não foi desejada, pois os pais eram jovens e não pretendiam se casar tão cedo. Logo, "A" nasceu apresentando o quadro de "fissura de palato" e com o "pés tortos", o que gerou uma grande preocupação familiar, já que era difícil lidar com uma criança que tinha muita dificuldade para mamar, tudo isso aliado à inexperiência de seus pais, sendo a mãe com 18 anos de idade e seu pai com 17.

Aos quatro anos de idade "A" ganhou uma irmã, onde às vezes reclamava que tudo era para ela, e que ela era perfeita.

No contexto escolar, nas primeiras letras não apresentou dificuldades no aprendizado, mas sempre foi inseguro, às vezes irritado, choro fácil, etc. Os pais o definiam como uma criança com muita energia, porém, semelhante às demais de sua idade.

Mas, "A" foi crescendo com idas à cidade de Bauru-SP para recompor a fissura de palato, e devido os pais terem muita pena dele, o mesmo foi sendo criado com poucos limites.

Aos 12 anos "A" foi diagnosticado com Transtorno do Déficit de Atenção com Hiperatividade e tomou o medicamento "Ritalina" por um bom tempo, mas os pais não se preocuparam em manter o tratamento, devido à falta de conhecimento sobre o TDAH, e com isso, os sintomas foram se agravando ao longo da adolescência. Na realidade, os pais de "A" não tinham noção do transtorno que o filho apresentava e nem mesmo sobre a gravidade do não tratamento. 
A partir daí, durante o ensino médio as dificuldades se intensificaram. "A" era disperso em sala de aula, brigava bastante com os professores, não obtinha boas notas, mas era de um círculo social de amigos muito grande. Ao se tornar um rapaz, "A" ainda tem dado muito trabalho, pois, começou a beber, comprar compulsivamente, mesmo sabendo que não terá condições de pagar, com isso, seu pai vive transtornado com as cobranças que recebe em seu trabalho das dívidas de "A".

Diante de tantas dificuldades, seus pais resolveram levá-lo a um psiquiatra, o qual medicou o jovem com Ritalina e o recomendou que fizesse academia para extravasar sua energia. Porém, com um mês de academia "A" resolveu que para ter um físico exemplar precisava tomar anabolizantes, os pais descobriram e tiraram " $\mathrm{A}$ " da academia, porque ele se recusava a fazer os exercícios sem tomar anabolizantes, e a partir daí, não foi mais à escola e não conseguiu terminar o ensino médio.

"A" teve algumas namoradas, mas não mantém um relacionamento por muito tempo por inconstância e imaturidade. Entra em alguns trabalhos, mas não fica por muito tempo por desatenção, começou a trabalhar em uma empresa para montagem de cabos de internet, mas não conseguiu permanecer, pois bateu com o carro duas vezes, a mãe sempre foi muito permissiva e o pai por motivo de trabalho não foi tão presente e também não era severo na educação de "A". Paralelo a tudo isso "A" ainda vive um conflito familiar, já que seus pais vivem sob a ameaça de uma separação iminente.

Atualmente, "A" resolveu ir morar com sua avó materna em Curitiba-PR., e a mesma tem tido alguns problemas de convivência com "A", mas, ele conseguiu um emprego em uma distribuidora de água, onde é muito querido por seus patrões, mesmo com alguns incidentes (bateu o carro também nesta empresa). Mas, "A" segue o curso de sua vida, ele é um bom rapaz, tem um bom coração, porém, deveria ter sido tratado ainda quando criança, para que hoje fosse um adulto com TDAH medicado, consciente e informado sobre o transtorno que apresenta.

\section{RESULTADOS E DISCUSSÃO}

Diante do caso analisado, tomou-se por base os estudos de Mattos (2001) e Goldstein (1996) para melhor compreensão dos fatos. Pois, segundo Mattos (2001), as atitudes que os pais têm em relação aos filhos com TDAH, contribuem para os 
comportamentos inadequados apresentados por eles. Na realidade, é difícil e desgastante lidar com um filho com esse transtorno, pois, os pais têm que estar sempre atentos no que ele está fazendo, gastar horas e horas acompanhando deveres de casa, estar sempre presente na escola, entre outros fatores. Algumas crianças com TDAH podem ter comportamento positivo e desafiador, complicando mais sua educação, bem como alguns pais querem resolver todos os problemas de uma só vez, com o objetivo de ajudar o seu filho. Mas, não há como modificar todos os comportamentos do filho ao mesmo tempo, tem que ser gradativamente.

De acordo com Mattos (2001, p.65), “é importante organizar as coisas de modo a ter certeza de que a criança vai ter uma boa chance de conseguir realizar o que está sendo exigido dela". Dessa maneira, é preciso começar a exigir coisas mais simples, fáceis de concluir, depois passar para algo mais difícil, assim, a criança sentirá mais confiança e motivada a repetir tais atividades. Pessoas com TDAH têm dificuldades de se motivar quando as recompensas são a longo prazo.

Na visão do autor, os portadores de TDAH necessitam de um acompanhamento constante dos pais por boa parte da infância e da adolescência para que se adaptem aos limites da vida na sociedade. A maior parte das pessoas que convivem com o portador de TDAH (incluindo pais e professores) tende a confundir incapacidade de fazer o correto com falta de desejo de fazer correto. Além disso, o TDAH pode ocasionar dificuldades na manutenção dos amigos e de relacionamentos afetivos de longa duração, como por exemplo, crianças podem entrar nas brincadeiras sem pedir permissão e, geralmente, não seguir as regras estabelecidas.

Mattos (2001) diz que, as pesquisas são bem claras, o TDAH não é resultado de um meio familiar tumultuado ou uma família disfuncional, embora, é claro, a criança venha a ter mais possibilidade de seus sintomas se agravarem. Por outro lado, as pesquisas também mostram que lares com crianças com TDAH são mais conturbados e estressados do que os outros lares. O problema existe, é neurobiológico, de origem genética, ninguém é culpado por ele, mas tem que ser aceito e enfrentado.

O impacto significativo e às vezes inesperado que a criança hiperativa tem sobre os membros da família e sobre a comunidade nunca é subestimado. Como observou o escritor e psicólogo Dr. John Taylor (Helping your hyperative child, Prima Publishers, 1990), as crianças hiperativas podem provocar a 'falência emocional' de uma família (GOLDSTEIN, 1996, p.122). 
Para o autor acima citado, devido à incapacidade da criança hiperativa de corresponder às expectativas dos pais, irmãos e comunidade, a criança forma um laço pai-mãe-filho, muito especial, e isto traz frequentes conflitos com os irmãos. Nesse sentido, Goldstein (1996), salienta sobre a pesquisa do Dr. Russell Barkley, o qual diz que, as famílias de crianças hiperativas vivenciam mais situações de divórcios e mais mudanças geográficas. Não se sabe se as dificuldades que a criança hiperativa traz contribuem para esse fator ou se este fator prova os problemas das crianças hiperativas. De uma maneira geral, as famílias de crianças hiperativas têm maior probabilidade de ter todas as espécies de problemas.

Goldstein (1996) também destaca a observação do escritor Dr. L. Eugene Arnold (Helping parents help their children, Brunner Mazel, 1978) quando diz que, a natureza crônica dos problemas da criança hiperativa não representa apenas um desgaste financeiro e emocional para a família, mas também esgota o tempo, a energia, as relações e a saúde mental da família. Um ponto importante a ressaltar é que, o pai tende a usar a força punitiva com seus filhos com maior frequência que a mãe, é também menos provável que o pai tente se empenhar numa repetida brincadeira verbal para conseguir que seu filho hiperativo realize alguma tarefa. Já a mãe tende a usar carinho para lidar com os problemas de comportamento, e por estas razões, a criança com TDAH pode reagir mais frequentemente ao pai do que a mãe.

Entretanto, para lidar melhor com o problema incurável do TDAH, Goldstein (1996) diz que, é fundamental, que os pais não apenas saibam como proceder, mas como interpretar tanto as informações desejadas sobre os problemas do filho quanto às soluções. De uma forma ou de outra, o filho continuará a vivenciar mais problemas no decorrer de sua vida, por isso, é necessário que os pais estejam cientes dos recursos que são úteis na identificação dos problemas e das maneiras para enfrentá-los, pois o filho com TDAH necessita dessa ajuda para ter êxito.

\section{CONSIDERAÇÕES FINAIS}

Diante do exposto neste trabalho, conclui-se que, o TDAH é um transtorno responsável pela enorme frustração que pais e seus filhos portadores desse distúrbio 
experimentam a cada dia. Pois, crianças, adolescentes e adultos hoje diagnosticados com TDAH são frequentemente rotulados de "problemáticos", "desmotivados", "indisciplinados", "irresponsáveis" ou, até mesmo, "pouco inteligentes", por essas razões merece ser tratado e diagnosticado o mais rápido possível.

Mas, a maioria do que se lê ou se ouve sobre o assunto tem uma conotação negativa, e a razão para isso é o fato do TDAH continuar sendo pouco conhecido pela maioria da população, mesmo apesar dos estudos a respeito terem se intensificado nas últimas décadas e a prática ter mostrado que até $5 \%$ das crianças em idade escolar podem ser incluídas nesse diagnóstico.

Diante disso, vale ressaltar que, o papel dos pais e, sobretudo, do professor, é fundamental para auxiliar no diagnóstico do TDAH, visto que, este transtorno fica mais evidente no período escolar, quando é preciso aumentar o nível de concentração para aprender. Nesse sentido, é preciso aplicar uma ação didático-pedagógica visando estimular a auto-estima, considerando a falta de concentração, criando atividades diversificadas para que não haja um comprometimento durante a aprendizagem.

Além disso, é essencial que os pais compreendam que este transtorno, necessita de tratamento, caso contrário, gera inúmeras complicações para seu portador no convívio familiar, social e emocional, levando à depressão, à busca de drogas, à insatisfação e à infelicidade, além de um conflito interno por não atender as mínimas atividades do dia a dia, e a rejeição gerada pelos demais companheiros de seu convívio. Por tudo isso, tem-se clareza de que, impor limites ao portador de TDAH é fator necessário e fundamental, pois o indivíduo vive numa sociedade cheia de regras, porém, não deve se prevalecer desta patologia para complicar a vida das pessoas, visto que, hoje em dia com o avanço das pesquisas sobre o TDAH, o tratamento ameniza bastante os sintomas, proporcionando ao portador uma vida mais tranquila.

\section{REFERÊNCIAS BIBLIOGRÁFICAS}

BANCO de Saúde. TDAH. (2010). Disponível em: <http://www.bancodesaude.com.br/tdah/tdah> Acesso em: 18/07/2011.

GOLDSTEIN, S. GOLDSTEIN, M. Hiperatividade: como desenvolver a capacidade de atenção da criança. 2. ed. Campinas: Papirus, 1996. 
GOTAH, Grupo de Orientação para o Déficit de Atenção/Hiperatividade. TDAH: um transtorno quase desconhecido. São Paulo: GOTAH, 2001.

MATTOS, P. No mundo a lua: perguntas e respostas sobre transtorno do déficit de atenção com hiperatividade em crianças, adolescentes e adultos. São Paulo: Lemos Editorial, 2001.

ROHDE, L. A. P.; BENCZIK, E. B. P. Transtorno de déficit de atenção e hiperatividade: o que é? como ajudar? Porto Alegre: Artes Médicas Sul, 1999. 